\title{
Neuronal Ensembles in Amygdala, Hippocampus, and Prefrontal Cortex Track Differential Components of Contextual Fear
}

\author{
Moriel Zelikowsky, ${ }^{1}$ Sarah Hersman, ${ }^{1}$ Monica K. Chawla, ${ }^{2}$ Carol A. Barnes,,${ }^{2,3}$ and Michael S. Fanselow ${ }^{1}$ \\ ${ }^{1}$ Departments of Psychology, Psychiatry \& Biobehavioral Sciences, and Integrative Center for Learning and Memory, University of California, Los Angeles, \\ California 90095, ${ }^{2}$ Evelyn F. McKnight Brain Institute and ${ }^{3}$ Departments of Psychology, Neurology \& Neuroscience, University of Arizona, Tucson, Arizona \\ 85724
}

\begin{abstract}
Although the circuit mediating contextual fear conditioning has been extensively described, the precise contribution that specific anatomical nodes make to behavior has not been fully elucidated. To clarify the roles of the dorsal hippocampus (DH), basolateral amygdala (BLA), and medial prefrontal cortex (mPFC) in contextual fear conditioning, activity within these regions was mapped using cellular compartment analysis of temporal activity using fluorescence in situ hybridization (catFISH) for Arc mRNA. Rats were delay-fear conditioned or immediately shocked (controls) and thereafter reexposed to the shocked context to test for fear memory recall. Subsequent catFISH analyses revealed that in the $\mathrm{DH}$, cells were preferentially reactivated during the context test, regardless of whether animals had been fear conditioned or immediately shocked, suggesting that the DH encodes spatial information specifically, rather then the emotional valence of an environment. In direct contrast, neuronal ensembles in the BLA were only reactivated at test if animals had been fear conditioned, suggesting that the amygdala specifically tracks the emotional properties of a context. Interestingly, Arc expression in the mPFC was consistent with both amygdala- and hippocampus-like patterns, supporting a role for the mPFC in both fear and contextual processing. Collectively, these data provide crucial insight into the region-specific behavior of neuronal ensembles during contextual fear conditioning and demonstrate a dissociable role for the hippocampus and amygdala in processing the contextual and emotional properties of a fear memory.
\end{abstract}

Key words: amygdala; Arc; catFISH; contextual fear; hippocampus; prefrontal cortex

\section{Introduction}

For contextual fear conditioning to proceed, an animal must form an integrated representation of a context, a representation of an emotional experience, and an association between the two. This ability is crucial, as contextual factors exert dramatic influence over the formation of emotional memories. To investigate what brain regions contribute to these functions, brain-wide activity was mapped using catFISH (cellular compartment analysis of temporal activity using fluorescence in situ hybridization), which provides a visualization of the neuronal populations involved in two, temporally distinct events as indexed by the local-

\footnotetext{
Received Aug. 25, 2013; revised March 26, 2014; accepted April 18, 2014

Author contributions: M.Z., C.A.B., and M.S.F. designed research; M.Z., S.H., and M.K.C. performed research; M.Z. and S.H. analyzed data; M.Z., C.A.B., and M.S.F. wrote the paper.

This work was supported by National Institutes of Health Grant R01 MH62122 (M.S.F.), a National Alliance for Research in Schizophrenia and Affective Disorders Distinguished Investigator Award \#18667 (M.S.F.), an American Psychological Association Dissertation Research Award (M.Z.), and the McKnight Brain Research Foundation (C.A.B.). We thank James Lister, Lan Hoang, and Timothy Hast for technical assistance.

The authors declare no competing financial interests.

Correspondence should be addressed to Michael S. Fanselow, Psychology Department, University of California, Los Angeles, 405 Hilgard Avenue, Los Angeles, CA 90095-1563. E-mail: mfanselow@gmail.com

M. Zelikowsky's present address: Department of Biology and Biological Engineering, California Institute of Technology, 1200 E. California Boulevard, Pasadena, CA 91125.

DOI:10.1523/JNEUROSCI.3624-13.2014

Copyright $\odot 2014$ the authors $\quad 0270-6474 / 14 / 348462-05 \$ 15.00 / 0$
}

ization of Arc mRNA within the nucleus and/or cytoplasm of a cell (Guzowski et al., 1999; Vazdarjanova and Guzowski, 2004). This makes catFISH an excellent tool for simultaneously investigating the behavior of neuronal ensembles in multiple brain structures implicated in context fear. In particular, we focused on the role of the dorsal hippocampus (DH), basolateral amygdala (BLA), and medial prefrontal cortex (mPFC), as these regions have been implicated in contextual fear (Zelikowsky et al., 2013).

Despite advances in understanding the neural circuitry underlying contextual fear, the exact contribution made by each brain region lacks clarity. Although the $\mathrm{DH}$ has long been implicated in the contextual and spatial processing required for contextual fear (Kim and Fanselow, 1992; Fanselow, 2000), the role of the DH in encoding the aversive component of a contextual fear memory is still unsettled. Several lines of evidence suggest that the hippocampus is critical for learning about context, but not the context-shock association (Fanselow, 2000; Matus-Amat et al., 2004), whereas others have suggested that the $\mathrm{DH}$ is important for encoding the context-shock association (Strekalova et al., 2003; Lepicard et al., 2006).

Although the BLA has long been known to be the hub of fear memory (Maren and Fanselow, 1996; Fanselow and LeDoux, 1999), it is still unclear whether its role in contextual fear conditioning is to represent emotional significance, context-shock as- 
A

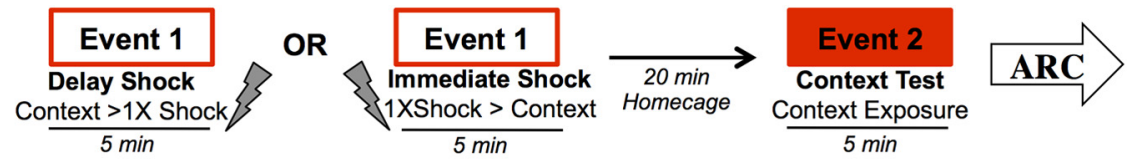

B

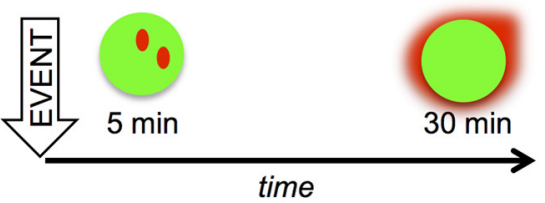

C

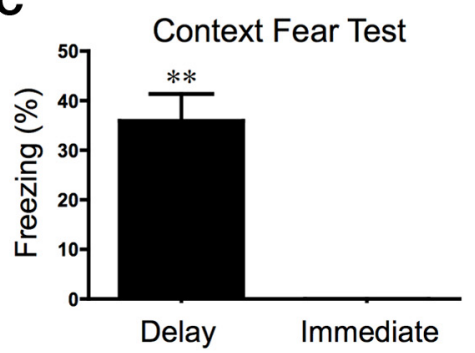

Figure 1. A, Behavioral design. Rats were fear conditioned or immediately shocked (Event 1) and 20 min later were tested for context fear (Event 2). B, Time course of Arc mRNA transcription and translocation from the nucleus of a cell to the cytoplasm. $\boldsymbol{C}$, Mean ( \pm SEM) percentage freezing during context test (Event 2). Delay-conditioned rats show significant freezing to the context compared with immediately shocked rats displaying the immediate shock deficit. ${ }^{* *} p<0.01$.

sociations, or simply to reflect arousal that modulates memory formation in other structures (Cahill et al., 1999; Fanselow and LeDoux, 1999).

Both causal manipulations and activity measures have implicated the mPFC in context fear, but its role in encoding contextual information, as opposed to a context-shock association, has not been examined. We examined the behavior of neuronal ensembles in the infralimbic (IL) and prelimbic (PL) regions of the $\mathrm{mPFC}$, because these regions have been implicated in contextual fear (Morgan and LeDoux, 1999; Frankland et al., 2004; Frankland and Bontempi, 2006; Quinn et al., 2008; Zelikowsky et al., 2013).

We combined catFISH analyses with a contextual fear conditioning paradigm capable of dissociating the effects of shock and context exposure from fear (immediate shock deficit; Fanselow, 1990). Rats were exposed to the context for 5 min (Event 1) and shocked either immediately or at the end of the $5 \mathrm{~min}$ (delay). Twenty minutes later, they were reexposed to the same context for 5 min (Event 2; Fig. 1A). Brains were subsequently taken and catFISH analyses performed to assess activation profiles within the DH, BLA, IL and PL.

\section{Materials and Methods}

Subjects. Forty-eight naive male Long-Evans rats, weighing 270-300 g (Harlan) were individually housed and maintained on a $12 \mathrm{~h}$ light/dark cycle with access to food and water ad libitum. Animals were handled daily for at least 1 week before the start of behavioral testing. The procedures used were in accordance with policy set and approved by the Institutional Animal Care and Use Committee of the University of California, Los Angeles.

Apparatus. Behavioral training utilized a set of four identical fear conditioning chambers $(30 \times 25 \times 25 \mathrm{~cm}$; Med Associates), equipped with a Med Associates VideoFreeze system. Individual boxes were enclosed in sound-attenuating chambers in a dedicated experimental room.

The context was comprised of chambers with aluminum sidewalls and a Plexiglas rear wall with blue dots. The grid floor consisted of 16 stainless steel rods $(4.8 \mathrm{~mm}$ thick) spaced $1.6 \mathrm{~cm}$ apart (center to center). Pans underlying each box were sprayed with a thin film of Simple Green to provide the context with a scent. Chambers were individually lit from above by white lights and cleaned with $70 \%$ isopropyl alcohol in between squads. Fans mounted above each chamber provided background noise $(60 \mathrm{~dB})$. The experimental room was brightly lit with overhead lights. Animals were transported to the context in squads of two or four in their home cages, which were slid onto hanging racks mounted to a portable cart and covered with a white sheet. Chambers were cleaned with a $10 \%$ bleach solution following each day of behavioral testing.

Fear conditioning. Animals were given either a delayed or an immediate shock in the first training session (Event 1 ) and tested for context fear 20 min later (Event 2). The delay procedure was used to generate conditioning while the immediate procedure took advantage of the immediate shock deficit (Fanselow, 1986; Fanselow et al., 1993) to control for exposure to shock and context in a manner that did not support fear conditioning. For the Delay group, animals were allowed to explore the context for $5 \mathrm{~min}$, which coterminated with a 2 s, $0.9 \mathrm{~mA}$ footshock. For the Immediate group, rats received the same 5 min exposure and shock; however, they were shocked immediately upon placement in the chamber. Rats were transported back to their home cages such that 20 min elapsed from the end of training (Event 1) to the start of testing (Event 2). During testing, animals were returned to the context for another $5 \mathrm{~min}$ exposure session during which freezing behavior was assessed. Immediately upon termination of testing, rats were killed and tissue was processed for in situ hybridization. To test for Arc signal bleed-through across time points, control rats were given only one $5 \mathrm{~min}$ context exposure session, either 30 or 5 min before being killed.

Fluorescence in situ hybridization. Within $30 \mathrm{~s}$ of the termination of testing, animals were decapitated and brains were frozen in isopentane, cooled over an ethanol/dry ice bath, and stored at $-80^{\circ} \mathrm{C}$ until sectioning. Coronal sections, $20 \mu \mathrm{m}$ thick, through the dorsal hippocampus, amygdala, and medial prefrontal cortex were cut and arranged on a slide. Negative and positive control animals were included, and their brains were sectioned and mounted alongside those of experimental rats to ensure that Arc signal was consistent within and across slides. Negative controls remained in their home cage throughout the experiment (home cage controls) until they were killed, and positive control rats were given seizures induced by pentylenetetrazol $(50 \mathrm{mg} / \mathrm{kg}) 5 \mathrm{~min}$ before being killed. Sections were stored at $-80^{\circ} \mathrm{C}$. Riboprobes were generated from the full-length Arc c-DNA ( 3.0 kbp transcript; Lyford et al., 1995) using a commercial RNA transcription kit (Maxiscript; Ambion) and RNA labeling nucleotide mix containing digoxigenin-tagged UTP (Roche Molecular Biochemicals). Fluorescence in situ hybridization was performed as described by Chawla et al. (2005).

Confocal microscopy and cellular analysis. Images were collected using a Zeiss 510 Metaseries laser scanning confocal microscope equipped with a Plan Apo $40 \times$ oil-immersion objective, numerical aperture 1.3. Photomultiplier tube assignments, pinhole size, detector gain, and offsets were kept constant after initial optimization for each slide. The $20 \mu \mathrm{m}$ tissue sections were digitized in $1.00 \mu \mathrm{m}$ optical planes and saved for later analysis. Image analysis was conducted using MetaMorph imaging software (Molecular Devices). Arc mRNA-positive cells were classified as: (1) foci + if there were one or two intense intranuclear transcription foci present in at least three planes; (2) cytoplasmic + if fluorescence product was located anywhere within at least $60 \%$ of the nuclear boundary; (3) double + where both intranuclear foci and cytoplasmic staining were present; or (4) negative where no Arc-related fluorescence staining was observed. Observers were blind to the experimental groups.

Statistical analysis. Freezing behavior was assessed using automated near infrared video tracking equipment and computer software (VideoFreeze, Med Associates), as previously described (Zelikowsky et al., 2013). Average percentage freezing and percentage Arc + cells per cellular compartment/total cells were statistically analyzed using betweensubjects ANOVAs and repeated-measures ANOVAs where appropriate. 
A
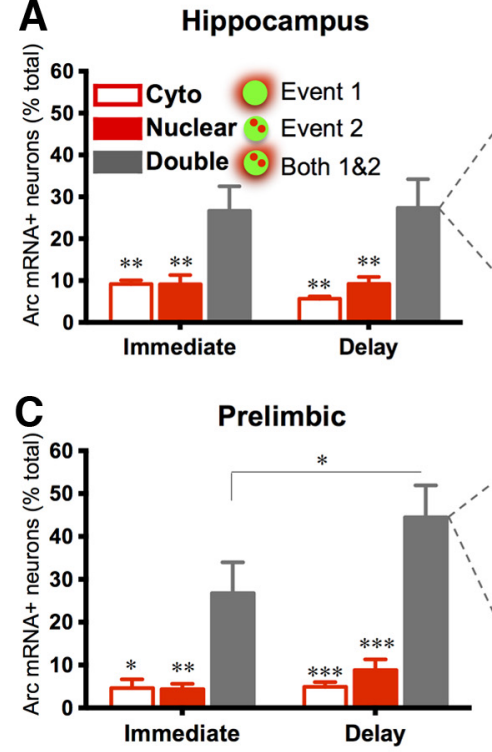

B
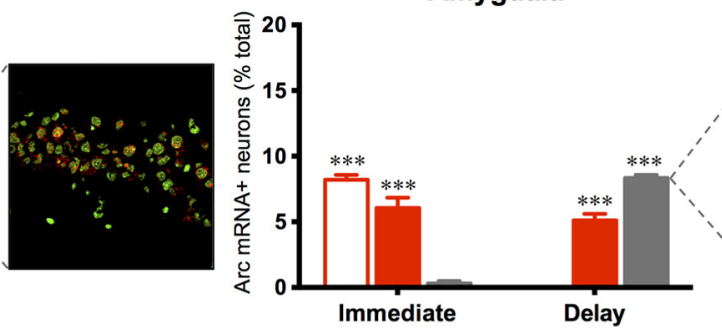

Infralimbic

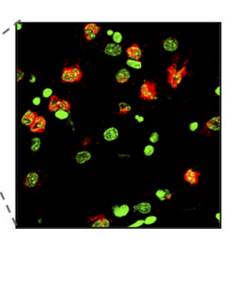

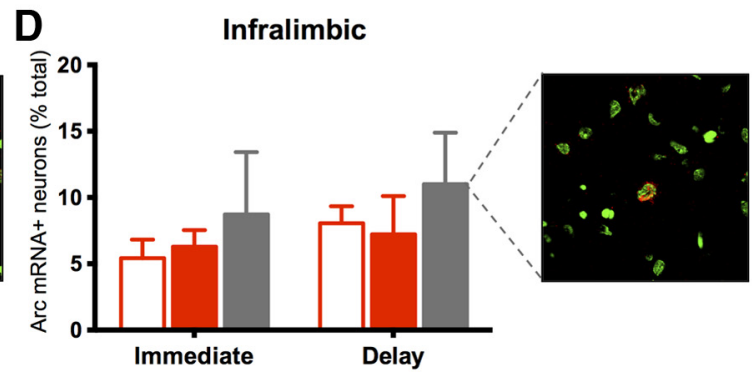

Figure 2. Mean ( \pm SEM) percentage total neurons (sytox; green) that were positive for Arc mRNA (red) in a given cellular compartment, and representative fluorescent images. $A$, CA1 region of DH. Animals showed a significant increase in double-labeled cells (gray) in the DH, regardless of whether or not the environment was fear inducing (Immediate vs Delay). $\boldsymbol{B}$, Cells in the BLA were only double labeled if animals were afraid (Delay group). C, Arc expression in PL cortex revealed overlap in neuronal ensembles involved in both events, which was further enhanced in fear-conditioned rats. $\boldsymbol{D}$, Levels of Arc expression in the IL cortex showed no compartmental differences. ${ }^{* * *} p<0.001,{ }^{* *} p<0.01,{ }^{*} p<0.05$.

Post hoc tests (Bonferroni) were performed following significant findings. The level of significance used was $p<0.05$.

\section{Results}

\section{Intact contextual fear and the immediate shock deficit}

Rats were subjected to behavioral testing that was temporally consistent with that required for catFISH analyses (Fig. 1). Twenty minutes after delay or immediate shock exposure, rats were tested for context fear for $5 \mathrm{~min}$. Rats that received a delayed shock froze to the context, while immediately shocked rats $\operatorname{did} \operatorname{not}(t=6.60 ; p<0.01$; Fig. $1 C)$. Thus, we were able to generate strong evidence for conditioning in the delay animals and the immediate shock deficit at a very short retention interval (20 $\mathrm{min}$ ). This preservation of behavioral effects is important because this memory is presumably undergoing cellular consolidation at the time of testing (Schafe et al., 1999, 2001) and levels of contextual fear could have potentially been altered at this short retention interval.

Neuronal ensembles in dorsal CA1 track spatial information Analysis of $A r c$ signal within CA1 indicated a significant effect of cellular compartmentalization of Arc (Fig. $2 A, F_{(2,18)}=15.72$; $p<0.001$ ), with no group effect (immediate vs delay) or interaction between compartment and group $(F$ values $<1)$. This consisted of a sharp increase in CA1 DH cells that were activated by both events (double-labeled) compared with those only activated by the first event (cytoplasmic Arc only) or only by the second event (nuclear Arc only; Double vs Cyto Immediate: $t=3.21, p<$ 0.01; Delay: $t=3.97, p<0.01$; Double vs Nuclear. Immediate: $t=3.20, p<0.01$; Delay: $t=3.31, p<0.01)$. Despite the presence of shock in the environment, Arc expression in CA1 showed a pattern similar to that previously exhibited for rats simply exposed to the same neutral environment twice (Guzowski et al., 1999), albeit with slightly lower overall Arc expression, perhaps as a result of the smaller fear conditioning boxes used in the results presented here. To ensure that Arc expression in the cytoplasm was specific to the first contextual experience rather than to a summation of both events, we ran an additional set of animals

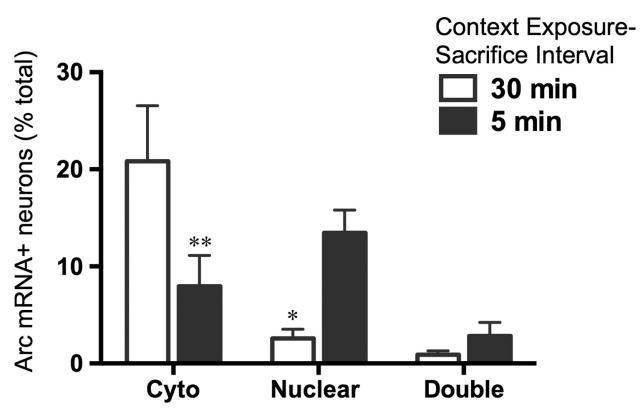

Figure 3. Mean ( \pm SEM) percentage total neurons that were positive for Arc mRNA in a given cellular compartment of dorsal CA1. Rats were exposed to the context for $5 \mathrm{~min}, 30$ or 5 min before being killed. Arc expression in the cytoplasm of rats exposed 30 min prior was significantly greater than that seen in the nucleus or in both compartments. ${ }^{* *} p<0.001$.

that received a 5 min context exposure event either 30 or 5 min before being killed (Fig. 3). Consistent with our fear conditioning data, rats that were exposed to the context 30 min prior without any subsequent experiences showed a significant increase in Arc signal in the cytoplasm compared with the nucleus $(t=4.41, p<$ $0.001)$ or double-labeled cells $(t=4.81, p<0.001)$. These data further support the idea that CA1 is strongly activated by contextual exposure, regardless of whether an emotional event occurs in that environment.

It is important to note that our analyses were restricted to the dorsal CA1 subregion of the hippocampus. We chose this subregion because it has been implicated specifically in context fear. For example, only deletions of NMDA receptors that are selective to CA1 cause a general loss of context fear (Shimizu et al., 2000). Furthermore, previous catFISH studies have demonstrated that Arc expression profiles in CA1 are more sensitive to differences between two environments than CA3 (Vazdarjanova and Guzowski, 2004). We examined dorsal as opposed to ventral hippocampus because $\mathrm{DH}$ is specifically involved in context and spatial learning, while the $\mathrm{VH}$ is more generally involved in emotional regulation. 


\section{Reactivation of BLA neurons depends on the formation of a context-shock association}

Arc expression in the BLA (analyses targeted toward basal nucleus) strongly contrasted with that seen in CA1 (Fig. $2 B$ ). There was no effect of group $\left(F_{(1,6)}=3.55, p>0.05\right)$; however, there was a main effect of cellular compartment $\left(F_{(2,12)}=5.23, p<\right.$ $0.05)$ and a significant interaction $\left(F_{(2,6)}=136.70, p<0.001\right)$. In contrast to the $\mathrm{DH}$, immediately shocked rats showed virtually no overlap between cells activated by the first and second context exposure (Double vs Cyto: $t=11.34, p<0.001$; Double vs Nuclear: $t=8.25, p<0.001$; Cyto vs Nuclear: $t=3.09, p<0.05)$. This pattern was completely reversed for animals that were fear conditioned (delay), wherein neurons that were activated during context conditioning (Event 1 ) were reactivated upon context fear testing (Event 2). Thus, there were virtually no cells positive for Arc in the cytoplasm only (Event 1), as these cells were always reactivated at test, thereby producing a significant increase in double-labeled compared with cytoplasmically labeled cells in the BLA $(t=12.00, p<0.001)$. In addition, a new population of BLA cells was recruited during the second, fear-expressing event, as the population of cells expressing Arc in the nucleus was significantly greater than those expressing Arc in the cytoplasm $(t=$ $7.34, p<0.001$ ), although not as high as the number of cells that were double-labeled with Arc in the nucleus and cytoplasm $(t=$ $4.66, p<0.01)$. This pattern of results suggests that the amygdala is specifically sensitive to an environment when it predicts danger, as neurons involved in the first event were only reactivated in animals that had been fear conditioned.

\section{mPFC neurons integrate contextual recognition and the context-shock association}

Figure $2 C$ depicts $A r c$ expression patterns in the PL region. Similar to catFISH analyses in the $\mathrm{DH}$, there was a significant overall effect of compartment $\left(F_{(2,12)}=31.99, p<0.01\right)$, but no group $\left(F_{(1,12)}=3.66, p>0.05\right)$ or interaction effects $\left(F_{(2,12)}=2.20, p>\right.$ $0.05)$. The increase in double-labeled cells was significant in fearconditioned rats (Double vs Nuclear: $t=5.83, p<0.001$; Double vs Cytoplasmic: $t=6.46, p<0.001$ ), as well as in immediately shocked rats (Double vs Nuclear: $t=3.66, p<0.01$; Double vs Cytoplasmic: $t=6.62, p<0.05)$. Like the DH, double-labeled cells in the immediately shocked animals indicate that some PL neurons represent context. Increased double labeling in delayed compared with immediate animals $(t=2.79, p<0.05)$ indicates that an additional population of PL neurons encode the contextshock association. This suggests that the PL region may combine information from the amygdala and hippocampus to guide behavior.

Lastly, Arc expression in the IL region (Fig. $2 D)$ revealed no differences between groups $\left(F_{(1,6)}=1.31, p>0.05\right)$ and no compartment or interaction effects $(F$ values $<1)$. This lack of difference likely reflects the relatively small number of IL cells activated following either delayed or immediate shock. This is consistent with the idea that the IL region is recruited specifically when contingencies are changed, as happens during extinction (Quirk and Milad, 2010).

\section{Discussion}

We examined whether the representation of an environment across different brain regions would be altered when the animal formed a context-shock association. Collectively, these data elucidate the differential contributions of various brain regions to contextual fear. Our results suggest that the DH selectively tracks the spatial information present in an environment, as opposed to the emotionally significant events that may occur there, regardless of movement or the emotional valence of the context. This is consistent with a specific and unique role for the dorsal portion of the hippocampus in cognitive as opposed to emotional processing (Fanselow and Dong, 2010). Importantly, we found that the "place-cell" type pattern of Arc activation observed in dorsal CA1 was equivalent in both afraid and unafraid rats, suggesting that the emotional valence of the environment rats acquired during the first event did not affect the manner in which the $\mathrm{DH}$ represented that environment when animals were reexposed to it. This ability to reactivate CA1 neuronal ensembles upon reexposure to the same context was maintained in our study using smaller contextual fear conditioning chambers, compared with the much larger exploration boxes standardly used in catFISH experiments looking at Arc expression in the DH (Vazdarjanova and Guzowski, 2004).

In addition, rats were able to display this CA1 pattern despite being shocked and regardless of whether or not they were freezing in that environment. Place cell activity is usually thought to require movement through a specific location. These findings suggest that even without substantial movement, CA1 neurons undergo activity sufficient to induce $A r c$ and allow recognition of the previously experienced environment. Previous studies found that $\sim 50 \%$ of place cells remap during tone fear conditioning (Moita et al., 2003), and that an environment that is first exposed and then fear conditioned results in reduced reactivation of hippocampal ensembles during the conditioning session (Nalloor et al., 2012). These findings suggest that the DH holds a mixed population of neurons-with some sensitive to the emotional experiences that occur in an environment and others not. However, the former study was limited by the small sample of neurons recorded from, the complication of a cued conditioning paradigm, and the lack of a group to control for changes due to shock administration itself, whereas the latter study examined reactivation of neuronal ensembles during fear conditioning that were first activated by a neutral context. In contrast, our study looked at cells that were first involved in fear conditioning and asked whether or not they were reactivated during the context fear test, allowing us to gauge whether fear conditioning of a context changed the way in which that context was subsequently represented across the brain. Consistent with our findings, a catFISH study (Barot et al., 2009) found no overlap in CA1 hippocampal neuronal ensembles when rats were continually exposed to an environment and subsequently shocked. However, this study also failed to separate the effects of shock from those of freezing, making it essential to reexamine the behavior of neuronal ensembles in the BLA and DH corresponding to the representation of contexts that have entered into an association with a shock.

In contrast to our hippocampal results, we found that the BLA was specifically sensitive to an environment when it predicts danger. Thus, the spatial and emotional properties of an environment seem to be differentially encoded by the DH and BLA, respectively. Indeed, every BLA cell activated by delay fear conditioning was reactivated upon reexposure to that context. Previously, Reijmers et al. (2007) found that BLA cells activated during Pavlovian fear conditioning were preferentially reactivated during retrieval, demonstrating that at least in the BLA, cells involved in conditioning are also involved in subsequent fear expression. However, this study was not extended to contextual fear conditioning and the contextual components therein. Our findings demonstrate that the same population of cells that are involved in encoding the initial contextual fear memory are also involved in the expression of that fear memory. The identity of these reactivated cells is left open by our analyses. One idea is that 
these are the population of CREB-expressing cells described by Silva, Josselyn, and colleagues (Kida et al., 2002; Josselyn et al., 2004; Han et al., 2007, 2009; Zhou et al., 2009). Another, interesting possibility not resolved by the data here is that contextual fear memories look very different when they are recalled after short compared with long retention intervals.

Whereas Arc expression in the DH and BLA reveals differential, nonoverlapping contributions to spatial and emotional processing aspects of fear conditioning, the pattern of Arc expression in the PL region suggests that this region may encode both aspects of context conditioning, as animals show an increase in doublelabeled cells following either immediate or delay shock. These results lead to the idea that there exists a population of placesensitive cells and fear-sensitive cells in the PL region. Despite the large number of PL neurons that were activated in our task, the IL neurons showed very little Arc induction. This is consistent with the suggestion that the roles of PL and IL neurons serve opposing functions (Quirk and Milad, 2010; Zelikowsky et al., 2013).

The ability of catFISH to provide information about the activation of entire populations of cells at two distinct time points combined with appropriate behavioral tasks and control procedures, allows for the functional dissection of distinct brain structures within a motivationally significant circuit. Therein, these data reveal the dissociable contribution that the hippocampus, amygdala, and prefrontal cortex make to contextual encoding, emotional processing, and the integration of both, highlighting the dedicated structure of brain regions and the necessity of their dynamic interactions to produce appropriate and adaptive behavior.

\section{References}

Barot SK, Chung A, Kim JJ, Bernstein IL (2009) Functional imaging of stimulus convergence in amygdalar neurons during Pavlovian fear conditioning. PLoS One 4:e6156. CrossRef Medline

Cahill L, Weinberger NM, Roozendaal B, McGaugh JL (1999) Is the amygdala a locus of "conditioned fear"? Some questions and caveats. Neuron 23:227-228. CrossRef Medline

Chawla MK, Guzowski JF, Ramirez-Amaya V, Lipa P, Hoffman KL, Marriott LK, Worley PF, McNaughton BL, Barnes CA (2005) Sparse, environmentally selective expression of Arc RNA in the upper blade of the rodent fascia dentata by brief spatial experience. Hippocampus 15:579-586. CrossRef Medline

Fanselow MS (1986) Conditioned fear-induced opiate analgesia: a competing motivational state theory of stress analgesia. Ann N Y Acad Sci 467: 40-54. CrossRef Medline

Fanselow MS (1990) Factors governing one-trial contextual conditioning. Anim Learn Behav 18:264-270. CrossRef

Fanselow MS (2000) Contextual fear, gestalt memories, and the hippocampus. Behav Brain Res 110:73-81. CrossRef Medline

Fanselow MS, Dong HW (2010) Are the dorsal and ventral hippocampus functionally distinct structures? Neuron 65:7-19. CrossRef Medline

Fanselow MS, LeDoux JE (1999) Why we think plasticity underlying Pavlovian fear conditioning occurs in the basolateral amygdala. Neuron 23: 229-232. CrossRef Medline

Fanselow MS, DeCola JP, Young SL (1993) Mechanisms responsible for reduced contextual conditioning with massed unsignaled unconditional stimuli. J Exp Psychol Anim Behav Process 19:121-137. CrossRef Medline

Frankland PW, Bontempi B (2006) Fast track to the medial prefrontal cortex. Proc Natl Acad Sci U S A 103:509-510. CrossRef Medline

Frankland PW, Bontempi B, Talton LE, Kaczmarek L, Silva AJ (2004) The involvement of the anterior cingulate cortex in remote contextual fear memory. Science 304:881-883. CrossRef Medline

Guzowski JF, McNaughton BL, Barnes CA, Worley PF (1999) Environmentspecific expression of the immediate-early gene Arc in hippocampal neuronal ensembles. Nat Neurosci 2:1120-1124. CrossRef Medline

Han JH, Kushner SA, Yiu AP, Cole CJ, Matynia A, Brown RA, Neve RL, Guzowski JF, Silva AJ, Josselyn SA (2007) Neuronal competition and selection during memory formation. Science 316:457-460. CrossRef Medline

Han JH, Kushner SA, Yiu AP, Hsiang HL, Buch T, Waisman A, Bontempi B, Neve RL, Frankland PW, Josselyn SA (2009) Selective erasure of a fear memory. Science 323:1492-1496. CrossRef Medline

Josselyn SA, Kida S, Silva AJ (2004) Inducible repression of CREB function disrupts amygdala-dependent memory. Neurobiol Learn Mem 82:159_ 163. CrossRef Medline

Kida S, Josselyn SA, Peña de Ortiz S, Kogan JH, Chevere I, Masushige S, Silva AJ (2002) CREB required for the stability of new and reactivated fear memories. Nat Neurosci 5:348-355. CrossRef Medline

Kim JJ, Fanselow MS (1992) Modality-specific retrograde amnesia of fear. Science 256:675-677. CrossRef Medline

Lepicard EM, Mizuno K, Antunes-Martins A, von Hertzen LS, Giese KP (2006) An endogenous inhibitor of calcium/calmodulin-dependent kinase II is up-regulated during consolidation of fear memory. Eur J Neurosci 23:3063-3070. CrossRef Medline

Lyford GL, Yamagata K, Kaufmann WE, Barnes CA, Sanders LK, Copeland NG, Gilbert DJ, Jenkins NA, Lanahan AA, Worley PF (1995) Arc, a growth factor and activity-regulated gene, encodes a novel cytoskeletonassociated protein that is enriched in neuronal dendrites. Neuron 14:433445. CrossRef Medline

Maren S, Fanselow MS (1996) The amygdala and fear conditioning: has the nut been cracked? Neuron 16:237-240. CrossRef Medline

Matus-Amat P, Higgins EA, Barrientos RM, Rudy JW (2004) The role of the dorsal hippocampus in the acquisition and retrieval of context memory representations. J Neurosci 24:2431-2439. CrossRef Medline

Moita MA, Rosis S, Zhou Y, LeDoux JE, Blair HT (2003) Hippocampal place cells acquire location-specific responses to the conditioned stimulus during auditory fear conditioning. Neuron 37:485-497. CrossRef Medline

Morgan MA, LeDoux JE (1999) Contribution of ventrolateral prefrontal cortex to the acquisition and extinction of conditioned fear in rats. Neurobiol Learn Mem 72:244-251. CrossRef Medline

Nalloor R, Bunting KM, Vazdarjanova A (2012) Encoding of emotionpaired spatial stimuli in the rodent hippocampus. Front Behav Neurosci 6:27. CrossRef Medline

Quinn JJ, Ma QD, Tinsley MR, Koch C, Fanselow MS (2008) Inverse temporal contributions of the dorsal hippocampus and medial prefrontal cortex to the expression of long-term fear memories. Learn Mem 15:368 372. CrossRef Medline

Quirk GJ, Milad MR (2010) Neuroscience: editing out fear. [Comment News]. Nature 463:36-37. CrossRef Medline

Reijmers LG, Perkins BL, Matsuo N, Mayford M (2007) Localization of a stable neural correlate of associative memory. Science 317:1230-1233. CrossRef Medline

Schafe GE, Nadel NV, Sullivan GM, Harris A, LeDoux JE (1999) Memory consolidation for contextual and auditory fear conditioning is dependent on protein synthesis, PKA, and MAP kinase. Learn Mem 6:97-110. Medline

Schafe GE, Nader K, Blair HT, LeDoux JE (2001) Memory consolidation of Pavlovian fear conditioning: a cellular and molecular perspective. Trends Neurosci 24:540-546. CrossRef Medline

Shimizu E, Tang YP, Rampon C, Tsien JZ (2000) NMDA receptordependent synaptic reinforcement as a crucial process for memory consolidation. Science 290:1170-1174. CrossRef Medline

Strekalova T, Zörner B, Zacher C, Sadovska G, Herdegen T, Gass P (2003) Memory retrieval after contextual fear conditioning induces c-Fos and JunB expression in CA1 hippocampus. Genes Brain Behav 2:3-10. CrossRef Medline

Vazdarjanova A, Guzowski JF (2004) Differences in hippocampal neuronal population responses to modifications of an environmental context: evidence for distinct, yet complementary, functions of CA3 and CA1 ensembles. J Neurosci 24:6489-6496. CrossRef Medline

Zelikowsky M, Bissiere S, Hast TA, Bennett RZ, Abdipranoto A, Vissel B, Fanselow MS (2013) Prefrontal microcircuit underlies contextual learning after hippocampal loss. Proc Natl Acad Sci U S A 110:9938-9943. CrossRef Medline

Zhou Y, Won J, Karlsson MG, Zhou M, Rogerson T, Balaji J, Neve R, Poirazi P, Silva AJ (2009) CREB regulates excitability and the allocation of memory to subsets of neurons in the amygdala. Nat Neurosci 12:1438 1443. CrossRef Medline 